\title{
Esophageal Motility Patterns After Peroral Endoscopic Myotomy in Patients With Achalasia
}

\author{
Zuzana Vackova, ${ }^{1,2 *}$ Jan Mares, ${ }^{1}$ Jana Krajciova, ${ }^{1,2}$ Zuzana Rabekova, ${ }^{1,2}$ Lucie Zdrhova, ${ }^{3}$ Pavla Loudova, ${ }^{4}$ Julius Spicak, ${ }^{1}$ \\ Petr Stirand, ${ }^{1}$ Tomas Hucl, ${ }^{1}$ and Jan Martinek ${ }^{1,2,5}$ \\ ${ }^{1}$ Department of Hepatogastroenterology, Institute for Clinical and Experimental Medicine, Prague, Czech Republic; ${ }^{2}$ Institute of Physiology, 1 st \\ Faculty of Medicine, Charles University, Prague, Czech Republic; ${ }^{3}$ Department of Internal Medicine, University Hospital Plzen, Czech Republic; \\ ${ }^{4}$ Department of Gastroenterology, Hospital Kolin, Czech Republic; and ${ }^{5}$ Ostrava University, Faculty of Medicine, Ostrava, Czech Republic
}

\section{Background/Aims \\ Several studies have reported partial recovery of peristalsis in patients with achalasia after myotomy. The aim of our study is to analyze esophageal motility patterns after peroral endoscopic myotomy (POEM) and to assess the potential predictors and clinical impact of peristaltic recovery.}

\section{Methods}

We performed a retrospective analysis of prospectively collected data of consecutive patients with achalasia undergoing POEM at a tertiary center. High-resolution manometry (HRM) studies prior to and after POEM were reviewed and the Chicago classification was applied.

\section{Results}

A total of 237 patients were analyzed. The initial HRM diagnoses were achalasia type I, 42 (17.7\%); type II, 173 (73.0\%); and type III, 22 (9.3\%). Before POEM, peristaltic fragments were present in 23 (9.7\%) patients. After POEM the Chicago classification diagnoses were: 112 absent contractility, 42 type I achalasia, 15 type II, 11 type III, 26 ineffective esophageal motility, 18 esophagogastric junction outflow obstruction, 10 fragmented peristalsis, and 3 distal esophageal spasm. Altogether 68 patients (28.7\%) had signs of contractile activity, but the contractions newly appeared in 47 patients (47/214, 22.0\%). Type II achalasia showed a trend for appearance of contractions $(P=0.097)$. Logistic regression analysis did not identify any predictors of peristaltic recovery. The post-POEM Eckardt score did not differ between patients with and without contractions nor did the parameters of timed barium esophagogram.

\section{Conclusions}

More than $20 \%$ of achalasia patients have signs of partial recovery of esophageal peristalsis after POEM. It occurs predominantly in type II achalasia but the clinical relevance seems to be negligible.

\section{(J Neurogastroenterol Motil 2021;27:205-214)}

\section{Key Words}

Esophageal achalasia; Manometry; Myotomy; Peristalsis

Received: June 3, 2020 Revised: August 28, 2020 Accepted: September 20, 2020

(a) This is an Open Access article distributed under the terms of the Creative Commons Attribution Non-Commercial License (http://creativecommons. org/licenses/by-nc/4.0) which permits unrestricted non-commercial use, distribution, and reproduction in any medium, provided the original work is properly cited.

*Correspondence: Zuzana Vackova, MD Department of Hepatogastroenterology, Institute for Clinical and Experimental Medicine, Videnska 1958/9, 14021 Prague, Czech Republic Tel: +420-2-6136-2617, E-mail: vackova.zuz@gmail.com 


\section{Introduction}

Achalasia is a primary motility disorder of the esophagus characterized by impaired deglutitive relaxation of the lower esophageal sphincter (LES) and disturbed peristalsis of the esophageal body. The ultimate cause of the motility disturbances is the loss of the inhibitory neurons of the myenteric plexus but the exact etiopathogenesis is unknown. Therefore, causal (and curative) treatment is not available. All of the current treatment modalities are symptomatic and targeted to alleviate the esophagogastric junction (EGJ) obstruction. Peroral endoscopic myotomy (POEM) is the most recent but already widely accepted treatment method for achalasia developed as a less invasive and fully endoscopic alternative to the traditional laparoscopic Heller's myotomy (LHM). ${ }^{1}$ Several studies assessing the impact of POEM on esophageal physiology showed an improved esophageal emptying (demonstrated on timed barium esophagogram [TBE]) and decreased integrated relaxation pressure (IRP), which is the main diagnostic high-resolution manometry (HRM) parameter. ${ }^{2-4}$ Similar outcomes were reported for other treatment modalities such as LHM or pneumatic dilation (PD). ${ }^{2,5,6}$

Nowadays, the HRM Chicago classification (CC) can recognize 3 clinically relevant subtypes of achalasia (I-III) that can be distinguished based on the pattern of esophageal contractility and pressurization in the esophageal pressure topography. Besides elevated IRP, which is the hallmark of achalasia, patients with type I have neither esophageal peristalsis nor pressurization, type II achalasia is characterized by the so-called pan-esophageal pressurizations, and type III presents with premature (spastic) contractions., ${ }^{7,8}$ Absent or impaired peristalsis of the esophageal body in achalasia patients had mostly been believed to be irreversible even though some early studies challenged this paradigm. ${ }^{9-11}$ Speculations are ongoing whether the absent (or impaired) peristalsis is a primary (consequence of loss of neurons) or secondary (consequence of outflow obstruction) phenomenon. Recently, partial peristaltic recovery after myotomy (either laparoscopic or endoscopic) in a considerable number of patients with achalasia has been described suggesting that EGJOO plays a role in occurrence of failed peristalsis in at least some patients with achalasia. ${ }^{11-18}$ Whether there are any predictors of peristaltic recovery and whether this phenomenon is clinically relevant is unknown.

The aim of our single-center study is to thoroughly assess the post-POEM esophageal motility patterns with regard to potential peristaltic recovery and its possible clinical relevance.

\section{Materials and Methods}

This was a retrospective analysis of prospectively collected data of patients who underwent POEM at our institution between December 2012 and December 2018. The POEM protocol has been approved by the Czech Health Ministry and by the local Ethical Committee (Docket No. 1251/16 [NM 12-01]). All patients signed an informed consent prior to the procedure.

\section{Patients}

All consecutive patients with confirmed achalasia referred to our tertiary center who underwent POEM, completed at least a 3-6 month follow-up and underwent HRM prior to and after POEM were included into the analysis. Patients with other spastic motility disorders such as EGJOO, jackhammer esophagus, and distal esophageal spasms were excluded, as well as the patients where any of the HRM data were missing.

\section{Methods}

Achalasia was diagnosed in all patients by upper gastrointestinal endoscopy, HRM, and TBE performed no longer than 6 months before the procedure. Symptom severity was assessed by the Eckardt score (0-12; Supplementary Table). ${ }^{19}$ Demographic data were also recorded. All patients were followed up according to a standardized protocol. The 3-month follow-up visit included upper endoscopy, HRM, TBE, and 24-hour pH monitoring. The Eckardt score assessed at 3-6 months was used for this analysis. Treatment success was defined as an Eckardt score $<3$.

\section{Peroral Endoscopic Myotomy Procedure}

POEM was performed under general anesthesia in a standard endoscopy room according to the original Inoue's technique. ${ }^{1}$ The procedures were performed by 3 endoscopists.

\section{High-resolution Manometry Procedures and High- resolution Manometry-studies Analysis}

HRM was performed at 3 tertiary centers (Institute for Clinical and Experimental Medicine, Prague, University Hospital Plzen, and Hospital Kolin). A solid-state catheter with an outer diameter of $4.2 \mathrm{~mm}$ and 36 circumferential sensors spaced at $1 \mathrm{~cm}$ intervals (ManoScan 360 High-Resolution Manometry device, Given Imaging, Los Angeles, CA, USA) was used for all measurements. The sensors were calibrated at $0-300 \mathrm{mmHg}$ prior to the measurement. The catheter was inserted transnasally with the distal 
sensors positioned in the stomach. The recordings were performed in the supine position using the standard protocol of 30 seconds resting period without swallowing and 10 wet swallows with $5 \mathrm{~mL}$ of water. HRM studies were analyzed using ManoView analysis software (Given Imaging).

All HRM studies were retrospectively reviewed and manually analyzed by a single physician (Z.V.). The mean LES resting pressure (LESP), mean IRP, and esophageal body motility patterns were assessed. Both pre-POEM and post-POEM motility was then classified according to the $\mathrm{CC}$ version $3.0 .^{20}$ Although the $\mathrm{CC}$ was developed and validated for patients without previous intervention on the esophagus, the descriptive character of assessment of esophageal motility based on automatically measured physical parameters enables application of this classification for categorizing the postinterventional motility findings as well, especially when the initial diagnosis is known. Achalasia was defined by manometric features of IRP $>15 \mathrm{mmHg}$ and impaired esophageal peristalsis. In patients with type I achalasia and those who had previously undergone treatment, the IRP threshold was lower if otherwise the clinical diagnosis including upper endoscopy and TBE corresponded with the diagnosis of achalasia. Type II achalasia was defined by panesophageal pressurization in at least $20 \%$ of the swallows and type III by presence of $\geq 20 \%$ spastic contractions (as defined in the latest CC). ${ }^{20}$ Peristaltic contractile activity after POEM was defined as the presence of at least $3 \mathrm{~cm}$ isobaric contour integrity of $20 \mathrm{mmHg}$ distal to the transition zone. Failed peristalsis (no peristaltic contractile activity) was defined as either $<3 \mathrm{~cm}$ or absent $20 \mathrm{mmHg}$ isobaric contour integrity.

\section{Outcomes}

The main outcome was the rate of post-POEM motility patterns with partial peristaltic activity.

Secondary outcomes were clinical significance of peristaltic recovery assessed by the Eckardt score and TBE parameters and identification of possible predictive factors.

\section{Statistical Methods}

Data are presented as counts and percentages or as means with standard deviations unless specified otherwise. The nonparametric Mann-Whitney $U$ test for continuous variables and the Fisher's exact test for factor variables were used to compare the data from independent samples (where patients were grouped according to a specific parameter). To compare variables among the 3 types of achalasia the Kruskal-Wallis $H$ test was used. Multilinear regression was performed to model the influence of the type of achalasia and previous treatment on the IRP. Confidence intervals for rates of different values in discrete variables were constructed by bootstrapping. Univariate analysis was performed to screen for predictive factors of esophageal contraction appearance after myotomy using both the Mann-Whitney $U$ test and logistic regression fitted for each variable. To compare the pre-POEM and post-POEM measures the non-parametric Wilcoxon's test was used. With regard to the exploratory character of the analysis, single test false discovery rate $P$-values are presented and values less than 0.05 were considered significant. The software packages SciPy version 1.3.1 for Python version 3.7.4 and Statsmodels version 0.10 .1 for Python version 2.7.16 were used for the statistical analysis.

\section{Results}

\section{Patients' and Procedure Characteristics}

From a total of 305 patients who underwent POEM from December 2012 until December 2018, 237 patients were included into the analysis (60 patients were excluded for incomplete examinations or missing data and 8 patients for other diagnosis

Table 1. Patients' Characteristics

\begin{tabular}{lc}
\hline $\begin{array}{c}\text { Demographic data and } \\
\text { characteristics }\end{array}$ & $\begin{array}{c}\text { Patients after POEM } \\
(\mathrm{n}=237)\end{array}$ \\
\hline Age (yr) & $48(16-82)$ \\
Gender (male/female) & $144 / 93$ \\
HRM diagnosis prior to POEM & \\
Achalasia type I & $42(17.7)$ \\
Achalasia type II & $173(73.0)$ \\
Achalasia type III & $22(9.3)$ \\
Previous treatment & $50(21.1)$ \\
PD only & 27 \\
Btx injection only & 2 \\
LHM only & 9 \\
PD + Btx & 2 \\
LHM + Btx & 0 \\
PD + LHM & 9 \\
LHM + PD + Btx & 1 \\
Pre-POEM Eckardt score & $7(3-12)$ \\
\hline
\end{tabular}

POEM, peroral endoscopic myotomy; HRM, high-resolution manometry; $\mathrm{PD}$, pneumatic dilation; Btx, botulinum toxin; LHM, laparoscopic Heller's myotomy.

Of total 305 patients after POEM, 8 patients of other diagnosis and 60 patients of incomplete data were excluded.

Data are presented as n, median (range), or n (\%). 
than achalasia). Fifty patients $(50 / 237,21.1 \%)$ had received a previous treatment (LHM, PD, and botulinum toxin injection) before POEM. A total of 183 patients (77.2\%) underwent POEM performed on the anterior wall, the remaining 54 patients (22.8\%) received POEM on the posterior wall. A statistically significant difference in the length of myotomy was between type I vs II $(10.4 \pm 2.2 \mathrm{~cm}$ vs $11.9 \pm 2.1 \mathrm{~cm}, P \leq 0.001)$ and I vs III (10.4 $\pm 2.2 \mathrm{~cm}$ vs $12.7 \pm 3.2 \mathrm{~cm}, P=0.002)$, but not between type II and III $(P=0.110)$. Patients' characteristics are summarized in Table 1.

\section{Esophagogastric Junction Characteristics}

The mean IRP before POEM was $28.9( \pm 13.3) \mathrm{mmHg}$. Twenty-three patients had IRP $<15 \mathrm{mmHg}$, in 13 patients the

Table 2. Comparison of Pre- and Post-peroral Endoscopic Myotomy Variables Among the High-resolution Manometry Subtypes of Achalasia

\begin{tabular}{|c|c|c|c|c|c|c|c|}
\hline \multirow{2}{*}{ HRM parameters and ES } & \multirow{2}{*}{ Type I } & \multirow{2}{*}{ Type II } & \multirow{2}{*}{ Type III } & \multirow{2}{*}{ All patients } & \multicolumn{3}{|c|}{$P$-value } \\
\hline & & & & & I vs II & I vs III & II vs III \\
\hline IRP pre (mmHg) & $21.5 \pm 11.3$ & $30.7 \pm 13.3$ & $28.5 \pm 10.4$ & $29.0 \pm 13.2$ & $<0.001$ & 0.009 & 0.257 \\
\hline LESP pre $(\mathrm{mmHg})$ & $32.1 \pm 15.9$ & $44.3 \pm 17.9$ & $44.0 \pm 3.8$ & $42.3 \pm 17.9$ & $<0.001$ & 0.002 & 0.398 \\
\hline Eckardt score pre & $6.5 \pm 2.2$ & $7.2 \pm 1.9$ & $5.9 \pm 1.9$ & $6.9 \pm 2.1$ & 0.0095 & 0.148 & 0.001 \\
\hline IRP post & $12.7 \pm 4.9$ & $13.5 \pm 5.9$ & $13.4 \pm 5.1$ & $13.4 \pm 5.7$ & 0.236 & 0.212 & 0.373 \\
\hline LESP post & $22.5 \pm 10.4$ & $23.3 \pm 9.6$ & $27.8 \pm 13.1$ & $23.6 \pm 10.2$ & 0.303 & 0.053 & 0.069 \\
\hline Eckardt score post & $0.5 \pm 0.7$ & $0.3 \pm 0.7$ & $0.5 \pm 1.4$ & $0.4 \pm 0.8$ & 0.075 & 0.118 & 0.322 \\
\hline
\end{tabular}

HRM, high-resolution manometry; ES, Eckardt score; IRP, integrated relaxation pressure; LESP, lower esophageal sphincter pressure; pre, before POEM; post, after POEM.

$P$-values obtained from Mann-Whitney $U$ test. $P<0.05$ is considered significant.

Data are presented as means $\pm \mathrm{SD}$.

Table 3. Pre- and Post-peroral Endoscopic Myotomy Motility Patterns According to the Chicago Classification

\begin{tabular}{|c|c|c|c|}
\hline Pre-POEM CC & Pre-POEM peristalsis & Post-POEM CC & $\begin{array}{c}\text { Peristaltic recovery } \\
\text { (newly appeared contractions) }\end{array}$ \\
\hline \multirow[t]{6}{*}{ Type I achalasia $(\mathrm{n}=42)$} & $0 / 42(0.0 \%)$ & Absent contractility (25) & \\
\hline & & Type 1 achalasia (11) & \\
\hline & & Type 2 achalasia (1) & \\
\hline & & $\operatorname{IEM}(3)$ & $5 / 42(11.9 \%)$ \\
\hline & & EGJOO (1) & \\
\hline & & Type 3 achalasia (1) & \\
\hline \multirow[t]{8}{*}{ Type II achalasia $(\mathrm{n}=173)$} & $1 / 173(0.5 \%)$ & Absent contractility (87) & \\
\hline & & Type 1 achalasia (30) & \\
\hline & & Type 2 achalasia (13) & \\
\hline & & $\operatorname{IEM}(17)$ & $42 / 172(24.4 \%)$ \\
\hline & & EGJOO (13) & \\
\hline & & Type 3 achalasia (6) & \\
\hline & & $\operatorname{DES}(2)$ & \\
\hline & & Fragmented peristalsis (4) & \\
\hline \multirow[t]{7}{*}{ Type III achalasia $(\mathrm{n}=22)$} & $22 / 22(100.0 \%)$ & Type 1 achalasia (1) & \\
\hline & & Type 2 achalasia (1) & \\
\hline & & Type 3 achalasia (4) & \\
\hline & & $\operatorname{IEM}(6)$ & \\
\hline & & Fragmented peristalsis (5) & \\
\hline & & EGJOO (4) & \\
\hline & & $\operatorname{DES}(1)$ & \\
\hline
\end{tabular}

POEM, peroral endoscopic myotomy; CC, Chicago classification; IEM, ineffective esophageal motility; EGJOO, esophagogastric junction outflow obstruction; DES, distal esophageal spasm. 
data were missing. The mean LESP was $42.3( \pm 17.9) \mathrm{mmHg}$. Both the initial IRP and LESP were significantly lower in patients who had already undergone previous treatment (IRP $20.3 \pm$ $9.2 \mathrm{mmHg}$ vs $31.3 \pm 13.1 \mathrm{mmHg}$, LES $30.0 \pm 10.6 \mathrm{mmHg}$ vs $45.5 \pm 18.0 \mathrm{mmHg} ; P<0.001)$. There were statistically significant differences with regard to both IRP and LESP among the achalasia subtypes before POEM (type I vs II and type I vs III; Table 2). Among patients with type I achalasia there was significantly higher proportion of patients $(17 / 42,40 \%)$ who had already undergone previous treatment compared to types II (30/173, 17\%; $P=0.003)$ and III $(3 / 22,14 \% ; P<0.001)$. Although the lowest IRP was observed in type I achalasia, multilinear regression has revealed that it is the proportion of patients who had undergone previous treatment that drives this difference more strongly than the manometric type I (previous treatment $P=0.071$ vs achalasia type I $P=0.120$ ). After POEM, the mean IRP decreased to 13.4 $( \pm 5.7) \mathrm{mmHg}(P<0.001)$ and normalized $(<15 \mathrm{mmHg})$ in 120/201 (59.7\%) patients. The LESP decreased to $23.6( \pm 10.2)$
$\operatorname{mmHg}(P<0.001)$

\section{Esophageal Motility Patterns}

The initial HRM diagnoses before POEM were as follows: type II achalasia in 173 patients (73.0\%), type I achalasia in 42 patients (17.7\%), and type III achalasia in 22 patients (9.3\%). Some esophageal peristaltic contractility was observed before POEM in 23 patients (9.7\%), almost exclusively in achalasia type III (22 patients), and in 1 patient with achalasia type II in whom swallows with clear contractions were alternating with swallows with panesophageal pressurization.

After POEM the esophageal motility patterns were reclassified according to the CC categories to 112 absent contractility, 42 type I achalasia, 15 type II achalasia, 11 type III achalasia, 26 ineffective esophageal motility (IEM), 18 EGJOO, 10 fragmented peristalsis, and 3 distal esophageal spasm (DES). The changes in the HRM findings and CC diagnosis before and after POEM are summarized in Table 3, examples of HRM studies in Figure 1.
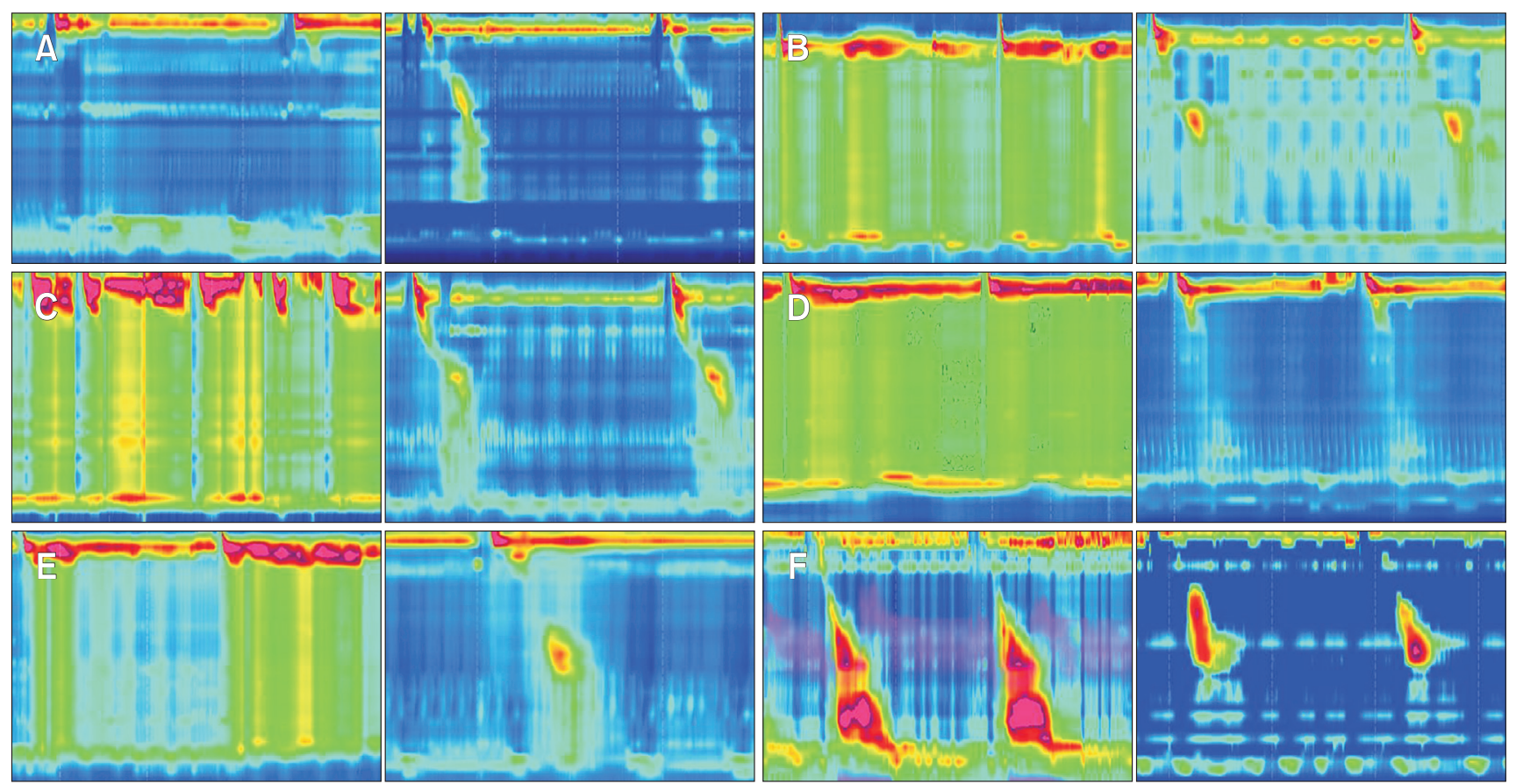

Figure 1. Examples of high-resolution manometry (HRM) findings before and after peroral endoscopic myotomy (POEM). (A) Type I achalasia before POEM (left) with integrated relaxation pressure (IRP) $21.5 \mathrm{mmHg}$, ineffective esophageal motility (peristaltic recovery) after POEM with IRP $10.6 \mathrm{mmHg}$ (right). (B) Type II achalasia before POEM (left) with IRP $32.8 \mathrm{mmHg}$, ineffective esophageal motility (peristaltic recovery) after POEM with IRP $11.7 \mathrm{mmHg}$ (right). (C) Type II achalasia before POEM (left) with IRP $46.4 \mathrm{mmHg}$, ineffective esophageal motility (peristaltic recovery) after POEM with IRP $12.5 \mathrm{mmHg}$ (right). (D) Type II achalasia before POEM with IRP $43.0 \mathrm{mmHg}$ (left), absent contractility after POEM with IRP $14.0 \mathrm{mmHg}$ (right). (E) Type II achalasia before POEM with IRP $27.3 \mathrm{mmHg}$ (left), ineffective esophageal motility (peristaltic recovery) after POEM with IRP $10.8 \mathrm{mmHg}$ (right). (F) Type III achalasia before POEM with IRP $30.8 \mathrm{mmHg}$ (left), fragmented peristalsis after POEM with IRP $12.7 \mathrm{mmHg}$ (right). 
Panesophageal pressurization observed in 180 patients prior to POEM (all patients with type II achalasia and 7 patients with type III) disappeared after myotomy in 160 patients (88.9\%), (154/173 [89.0\%] in type II, 6/7 [85.7\%] in type III). Compartmentalized pressurization observed in 14 patients with type III achalasia prior to POEM disappeared in all but 2 patients (both had IRP $>15$ $\mathrm{mmHg})$. In the group of patients with some peristaltic contractile activity observed prior to POEM $(\mathrm{n}=23)$ this also persisted after
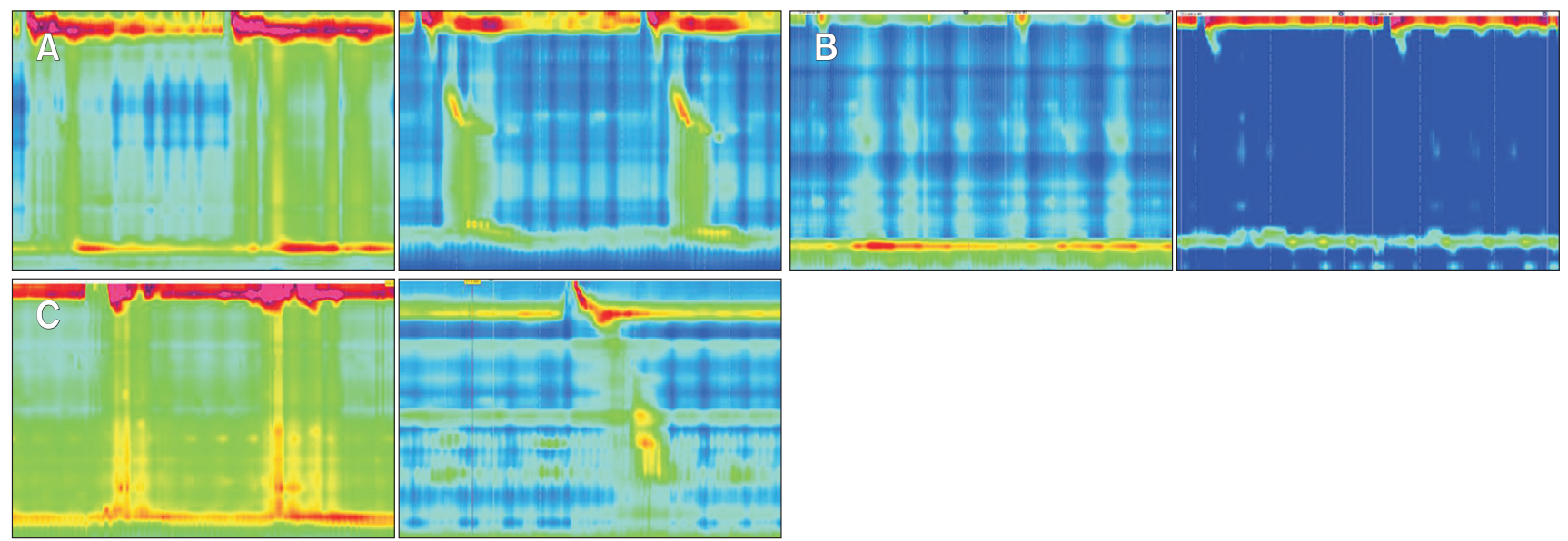

Figure 2. Examples of high-resolution manometry (HRM) findings in patients with post-peroral endoscopic myotomy (POEM) integrated relaxation pressure $(\mathrm{IRP})>15.0 \mathrm{mmHg}$. (A) Type II achalasia before POEM (left) with IRP $42.2 \mathrm{mmHg}$, esophagogastric junction outflow obstruction (EGJOO) (peristaltic recovery) after POEM with IRP $20.1 \mathrm{mmHg}$ (right). (B) Type I achalasia before POEM (left) with IRP 54.9 $\mathrm{mmHg}$, persisting type I achalasia after POEM with IRP $18.7 \mathrm{mmHg}$ (right). (C) Type II achalasia before POEM (left) with IRP 53.1 mmHg, EGJOO (peristaltic recovery) after POEM with IRP $17.5 \mathrm{mmHg}$ (right).

Table 4. Comparison of Pre- and Post-treatment Parameters in Groups of Patients With and Without Partial Peristaltic Recovery After Peroral Endoscopic Myotomy

\begin{tabular}{|c|c|c|c|c|c|}
\hline \multirow{2}{*}{$\begin{array}{c}\text { Assessed pre- and } \\
\text { post-POEM parameters }\end{array}$} & $\begin{array}{l}\text { No peristaltic recovery } \\
\qquad(\mathrm{n}=167)\end{array}$ & $\begin{array}{l}\text { Peristaltic recovery } \\
\qquad(\mathrm{n}=47)\end{array}$ & \multirow[t]{2}{*}{ Mean difference } & \multirow[t]{2}{*}{$P$-value ${ }^{\mathrm{a}}$} & \multirow[t]{2}{*}{$P$-value ${ }^{\mathrm{b}}$} \\
\hline & Mean \pm SD & Mean $\pm \mathrm{SD}$ & & & \\
\hline Age (yr) & $46.9 \pm 14.9$ & $47.2 \pm 14.7$ & -0.348 & 0.433 & 0.907 \\
\hline IRP pre (mmHg) & $27.8 \pm 13.5$ & $33.3 \pm 12.4$ & -5.498 & 0.003 & 0.051 \\
\hline IRP post $(\mathrm{mmHg})$ & $13.0 \pm 5.7$ & $14.7 \pm 5.5$ & -1.737 & 0.039 & 0.130 \\
\hline IRP red $(\mathrm{mmHg})$ & $14.8 \pm 12.9$ & $18.6 \pm 12.6$ & -3.777 & 0.013 & 0.159 \\
\hline Eckardt score pre & $7.1 \pm 2.1$ & $7.0 \pm 1.8$ & 0.039 & 0.459 & 0.925 \\
\hline Eckardt score post & $0.4 \pm 0.8$ & $0.3 \pm 0.6$ & 0.125 & 0.141 & 0.392 \\
\hline Eckardt score red & $6.6 \pm 2.2$ & $6.7 \pm 1.9$ & -0.115 & 0.311 & 0.786 \\
\hline LESP pre (mmHg) & $40.8 \pm 18.9$ & $46.3 \pm 14.6$ & -5.485 & 0.010 & 0.154 \\
\hline LESP post (mmHg) & $23.2 \pm 9.9$ & $23.2 \pm 9.4$ & -0.018 & 0.412 & 0.993 \\
\hline LESP red (mmHg) & $17.5 \pm 19.1$ & $23.5 \pm 15.7$ & -6.044 & 0.009 & 0.128 \\
\hline TBE 5 min pre $(\mathrm{cm})$ & $8.2 \pm 4.1$ & $7.6 \pm 4.2$ & 0.595 & 0.261 & 0.549 \\
\hline TBE 5 min post $(\mathrm{cm})$ & $1.3 \pm 2.5$ & $1.4 \pm 2.7$ & -0.021 & 0.295 & 0.968 \\
\hline TBE 5 min red $(\mathrm{cm})$ & $6.9 \pm 4.9$ & $5.9 \pm 4.5$ & 1.062 & 0.153 & 0.369 \\
\hline TBE width pre (cm) & $3.9 \pm 1.3$ & $3.4 \pm 1.3$ & 0.506 & $0.025^{\mathrm{a}}$ & 0.097 \\
\hline TBE width post $(\mathrm{cm})$ & $2.6 \pm 0.9$ & $2.6 \pm 1.9$ & 0.048 & $0.027^{\mathrm{a}}$ & 0.850 \\
\hline
\end{tabular}

IRP, integrated relaxation pressure; LESP, lower esophageal sphincter pressure; pre, before peroral endoscopic myotomy (POEM); post, after POEM; red, delta of the pre- and post-POEM value (ie, reduction after POEM) TBE 5 min, height of the column at 5 minutes on timed barium esophagogram, width. ${ }^{a} P$-values obtained from Mann-Whitney $U$ test. $P<0.05$ is considered significant.

${ }^{b}$ Logistic regression showed no predictive factors of the peristaltic recovery among the analyzed parameters. 
POEM in all but 2 patients. Majority of the patients with postPOEM IRP $>15 \mathrm{mmHg}$ had type II achalasia before the myotomy $(60 / 81,74.1 \%)$ while the HRM post-POEM diagnoses were: 37 achalasia type I, 18 EGJOO, 11 achalasia type II, 10 achalasia type III, and 5 absent contractility (examples of HRM studies in Fig. 2).

\section{Partial Peristaltic Recovery}

From 214 patients without any signs of peristaltic contractions before POEM (achalasia type I and all but one type II cases) some signs of esophageal peristalsis after POEM were encountered in 47 patients (22.0\%). The $\mathrm{CC}$ categories of these were 4 fragmented peristalsis, 7 achalasia type III, 2 DES, 14 EGJOO, and 20 IEM. Examples of HRM studies of different post-POEM HRM findings are shown in Figure 1.

Further, we compared the manometric parameters of the groups with $(\mathrm{n}=47)$ and without $(\mathrm{n}=167)$ partial peristaltic recovery. The pre-POEM IRP, LESP, and post-POEM IRP were significantly higher in those patients in which the esophageal contractions newly appeared after POEM, but none of those or other measured parameters has proven to be a significant predictor of peristaltic recovery in the logistic regression model (Table 4). Between the achalasia subtypes, peristaltic recovery occurred more often in type II (24.4\%; 95\% CI, $18.0-30.8 \%)$ vs type I (11.9\%; 95\% CI, $2.4-$ 23.8\%). However, the trend for more frequent peristaltic recovery in type II was not statistically significant $(P=0.097)$. Peristaltic recovery was significantly more frequent in patients with reflux esophagitis (RE) at the 3-months follow-up (29/72 [40.3\%] with $\mathrm{RE}$ vs $18 / 94$ [19.1\%] without RE; $P=0.032$ ). Peristaltic recovery occurred in similar frequencies in patients with anterior (38/129, $23 \%)$ or posterior $(9 / 38,19 \%)$ myotomy $(P=0.693)$ as well as in patients with short $(\leq 10 \mathrm{~cm})$ vs long $(>10 \mathrm{~cm})$ myotomy in types I and II $(P=0.745)$.

\section{Clinical Significance}

The mean Eckardt score before POEM was $6.9 \pm 2.1$. Treatment success at 3-6 months was achieved in 224 patients (224/231, $97.0 \%)$. The mean post-POEM Eckardt score was $0.4 \pm 0.8$. Interestingly, the Eckardt score was 0 also in the majority of the patients in which the post-POEM IRP did not normalize $(<15$ $\mathrm{mmHg} ; 60 / 80,75.0 \%)$. On the TBE the mean height of the column at 5 minutes significantly decreased from $7.9 \pm 4.2 \mathrm{~cm}$ prior to POEM to $1.4 \pm 2.5 \mathrm{~cm}$ after POEM $(P<0.001)$ and so did the maximum width from $3.7 \pm 1.3 \mathrm{~cm}$ to $2.6 \pm 1.2 \mathrm{~cm}(P<0.001)$. With regard to the peristaltic recovery, neither the post-POEM
Eckardt score nor the TBE parameters differed between the 2 groups of patients with and without contractions (Table 4).

\section{Discussion}

To our knowledge we present the largest series of patients with achalasia evaluated for post-POEM esophageal motility by HRM. Our main finding is that in $22.0 \%$ of patients after POEM the peristaltic or rather contractile activity in the esophageal body recovered after the obstruction of the EGJ was relieved, and it happened predominantly in type II achalasia (statistical trend). We did not find any association of this phenomenon with a symptomatic outcome.

Examining whether the esophageal peristalsis, generally not present or disturbed in patients with achalasia, may recover after relieving EGJ obstruction has 2 principal reasons. Firstly, it may provide deeper insight into the esophageal pathophysiology and help to elucidate whether the absent or abnormal peristalsis is a primary or secondary phenomenon. Secondly, if the peristaltic recovery occurs, it is still unclear whether it is clinically significant.

Recently, several rather small studies addressed the issue of possible recovery of peristalsis after myotomy either laparoscopic or endoscopic, most of them predominantly focusing on the measured HRM parameters (IRP and LESP) ${ }^{12,14,15,21}$ But the phenomenon of peristaltic recovery after alleviating the obstruction of EGJ has already been observed in the past including both clinical and experimental settings. ${ }^{9-11,13,17,18}$ In our study we have shown, that the esophageal contractions were observed in $28.7 \%$ of patients after POEM including cases who had some preserved peristalsis also before POEM (achalasia type III), thus the true "recovery" with the newly appeared contractions was observed in $22.0 \%$. This number is considerably lower compared to other studies assessing physiologic outcomes after myotomy, for example Teitelbaum et $\mathrm{al}^{4}$ reported $47.0 \%(8 / 21)$, and Roman et $\mathrm{al}^{12}$ even $57.0 \%$ patients with partial return of peristalsis after LHM and/ or POEM. The higher percentage in the latter study may partially be explained by inclusion of patients with type III achalasia, even if in these patients "newly" appearing peristaltic recovery cannot be observed. Other studies also reported the phenomenon of peristaltic recovery after LHM. ${ }^{11,17,18}$ Parrilla et a ${ }^{18}$ observed it in $46.6 \%$ of patients. However, in another post-LHM study, the peristalsis was restored in only $25.0 \%$ patients. ${ }^{11}$ Thus, there is no doubt about the presence of the phenomenon of partial peristaltic recovery after myotomy, but the data vary largely in terms of the proportion of patients experiencing recovery. Our study reports, so far, the lowest proportion of subjects with peristaltic recovery 
may be attributed to the considerably higher number of analyzed patients in our study (21-45 patients in other studies vs 237 in our study) and varying methodology used to assess peristaltic recovery.

Another interesting finding is that the type II achalasia (as opposed to type I) showed some predisposition for the peristaltic recovery. Although the proportion of patients with peristaltic recovery after POEM was twice as high in type II than in type I, the difference was not statistically significant $(P=0.097)$. This finding may provide a further insight into the pathogenesis of achalasia. We know that different HRM types respond to treatment differently, ${ }^{22,23}$ and histopathological studies revealed heterogeneity among the achalasia patients in terms of extent of loss and degeneration of the inhibitory neurons of myenteric plexus, and intensity of inflammation and fibrotic changes. ${ }^{2-28}$ It seems, that the type I ("classic" achalasia) may be a more progressed stage or more aggressive phenotype of the disease with a complete loss of ganglionic neurons, more pronounced fibrosis and completely absent peristalsis with almost no potential for recovery of contractility. Thus, achalasia type I may represent the most severe phenotype while the type III and probably also type II seem to have some differences in the pathogenetic pathways or at least the speed of the pathological processes. Moreover, type III achalasia presents as a distinct entity with quite well preserved, although disturbed, peristalsis, and more than $90.0 \%$ of these patients retain the contractile activity also after POEM, as shown in our study. Although $50.0 \%$ of patients with type II had absent contractility after POEM and $24.8 \%$ still fulfilled the criteria of achalasia, a not negligible number of patients (24.9\%) had some signs of peristalsis. This finding demonstrates that even the type II achalasia is a heterogenous group and brings out a question where these contractions are coming from. The hypothesis is that there may actually be a contractile reserve that is not seen before POEM due to the panesophageal pressurizations (that are in fact contractions of the longitudinal muscle layer), and that it is demasked when pressurization disappears with lowering the resistance of EGJ. If this is true, the proportion of patients with real peristaltic recovery will be even lower. This hypothesis would also go hand in hand with our finding that the pre-POEM IRP and LES pressure were significantly higher in patients with the partial peristaltic recovery, as the higher pressures may refer to the residual potential to contract.

Although the phenomenon of partial peristaltic recovery is not rare (but also probably not as frequent as reported earlier), the clinical impact in terms of symptomatic outcome is unknown. We have not proved the partial peristaltic recovery after POEM to have im- pact on the symptomatic outcome neither in esophageal emptying on TBE nor in terms of the Eckardt score. Interestingly, peristaltic recovery was more frequent in patients with RE after POEM than in patients without. The explanation of this finding is challenging and several hypotheses can be speculated to address the relation between post-POEM reflux and motility disturbances. Answering this question and also other post-POEM reflux-related complications requires further long-term investigation.

Our study has several limitations. First, the CC was developed for treatment-naïve patients only, thus for its application to assess and categorize the motility findings after POEM is not validated. On the other hand, the CC classifies the motility patterns based on the measured and automatically calculated parameters which are descriptive with regard to the esophageal pathophysiology. Therefore, knowing the initial diagnosis and the intervention, we believe the measures of the main HRM parameters can be compared and the CC applied as it was used elsewhere. ${ }^{12}$ Second, for the purpose of our study we used the term "peristaltic recovery." Obviously, it harbors inaccuracy in the term "peristaltic" because we cannot assess accurately enough whether these "recovered" contractions are truly peristaltic, ie, have the potential to propel the bolus distally. With this regard, the HRM impedance data would have been beneficial but, unfortunately, the impedance catheter was not available at our center until 2017. Third, it may be argued that for such a physiologic change, as partial peristaltic recovery is, the 3-month period is not sufficient and it would be interesting to assess the evolution of the motility patterns over time; however, it would require a dedicated study with patients willing to undergo the per se unnecessary HRM procedure again.

In summary, we demonstrated that peristaltic recovery is not an uncommon phenomenon, although it may not be as frequent as previously thought. The restoration of the contractile activity also seemed to be intertwined with the manometric subtypes of achalasia as shown in our study where the type II was more prone to show the contractile reserve (besides the obvious type III) than type I. Nevertheless, the peristaltic recovery was not associated with an improved symptomatic outcome. By extension, these findings tickle the hypothesis of possible different pathogenetic pathways in the 3 subtypes of achalasia and provide material for further research.

\section{Supplementary Material}

Note: To access the supplementary table mentioned in this article, visit the online version of Journal of Neurogastroenterol- 
ogy and Motility at http://www.jnmjournal.org/, and at https://doi. org/10.5056/jnm20126.

\section{Financial support: None.}

\section{Conflicts of interest: None.}

Author contributions: Zuzana Vackova designed the study, reviewed HRM studies, analyzed data, and drafted the manuscript; Jana Krajciova, Lucie Zdrhova, Pavla Loudova, Zuzana Rabekova, and Zuzana Vackova performed the HRM procedures; Jan Martinek designed the study and revised the manuscript critically; Tomas Hucl, Petr Stirand, and Jan Martinek performed POEM; Jan Mares analyzed the data and revised the manuscript critically; and Julius Spicak and Tomas Hucl revised the manuscript critically.

\section{References}

1. Inoue H, Minami H, Kobayashi $\mathrm{Y}$, et al. Peroral endoscopic myotomy (POEM) for esophageal achalasia. Endoscopy 2010;42:265271.

2. Werner YB, Hakanson B, Martinek J, et al. Endoscopic or surgical myotomy in patients with idiopathic achalasia. New Engl J Med 2019;381:2219-2229.

3. von Renteln D, Inoue H, Minami H, et al. Peroral endoscopic myotomy for the treatment of achalasia: a prospective single center study. Am J Gastroenterol 2012;107:411-417.

4. Teitelbaum EN, Soper NJ, Santos BF, et al. Symptomatic and physiologic outcomes one year after peroral esophageal myotomy (POEM) for treatment of achalasia. Surg Endosc 2014;28:3359-3365.

5. Moonen A, Annese V, Belmans A, et al. Long-term results of the European achalasia trial: a multicentre randomised controlled trial comparing pneumatic dilation versus laparoscopic Heller myotomy. Gut 2016;65:732-739.

6. Ponds FA, Fockens P, Lei A, et al. Effect of peroral endoscopic myotomy vs pneumatic dilation on symptom severity and treatment outcomes among treatment-naive patients with achalasia: a randomized clinical trial. JAMA 2019;322:134-144.

7. Pandolfino JE, Kwiatek MA, Nealis T, Bulsiewicz W, Post J, Kahrilas PJ. Achalasia: a new clinically relevant classification by high-resolution manometry. Gastroenterology 2008;135:1526-1533.

8. Bredenoord AJ, Fox M, Kahrilas PJ, Pandolfino JE, Schwizer W, Smout AJ. Chicago classification criteria of esophageal motility disorders defined in high resolution esophageal pressure topography. Neurogastroenterol Motil 2012;24(suppl 1):57-65.

9. Little AG, Correnti FS, Calleja IJ, et al. Effect of incomplete obstruction on feline esophageal function with a clinical correlation. Surgery 1986;100:430-436.
10. Schneider JH, Peters JH, Kirkman E, Bremner CG, DeMeester TR. Are the motility abnormalities of achalasia reversible? An experimental outflow obstruction in the feline model. Surgery 1999;125:498-503.

11. Zaninotto G, Costantini M, Anselmino M, Boccù C, Ancona E. Onset of oesophageal peristalsis after surgery for idiopathic achalasia. Br J Surg 1995;82:1532-1534.

12. Roman S, Kahrilas PJ, Mion F, et al. Partial recovery of peristalsis after myotomy for achalasia: more the rule than the exception. JAMA Surg 2013;148:157-164.

13. Tatum RP, Wong JA, Figueredo EJ, Martin V, Oelschlager BK. Return of esophageal function after treatment for achalasia as determined by impedance-manometry. J Gastrointest Surg 2007;11:1403-1409.

14. Lu B, Li M, Hu Y, Xu Y, Zhang S, Cai LJ. Effect of peroral esophageal myotomy for achalasia treatment: a Chinese study. World J Gastroenterol 2015;21:5622-5629.

15. Salvador R, Savarino E, Pesenti E, et al. Effects of laparoscopic myotomy on the esophageal motility pattern of esophageal achalasia as measured by high-resolution manometry. Surg Endosc 2017;31:35103518.

16. Huh CW, Youn YH, Chung H, Lee YC, Park H. Functional restoration of the esophagus after peroral endoscopic myotomy for achalasia. PLoS One 2017;12:e0178414.

17. Patti MG, Galvani C, Gorodner MV, Tedesco P. Timing of surgical intervention does not influence return of esophageal peristalsis or outcome for patients with achalasia. Surg Endosc 2005;19:1188-1192.

18. Parrilla P, Martinez de Haro LF, Ortiz A, Morales G, Garay V, Aguilar $\mathrm{J}$. Factors involved in the return of peristalsis in patients with achalasia of the cardia after Heller's myotomy. Am J Gastroenterol 1995;90:713717.

19. Eckardt VF, Aignherr C, Bernhard G. Predictors of outcome in patients with achalasia treated by pneumatic dilation. Gastroenterology 1992;103:1732-1738.

20. Kahrilas PJ, Bredenoord AJ, Fox M, et al. The Chicago Classification of esophageal motility disorders, v3.0. Neurogastroenterol Motil 2015;27:160-174.

21. Hu Y, Li M, Lu B, Meng L, Fan Y, Bao H. Esophageal motility after peroral endoscopic myotomy for achalasia. J Gastroenterol 2016;51:458464.

22. Pandolfino JE, Fox MR, Bredenoord AJ, Kahrilas PJ. High-resolution manometry in clinical practice: utilizing pressure topography to classify oesophageal motility abnormalities. Neurogastroenterol Motil 2009;21:796-806.

23. Andolfi C, Fisichella PM. Meta-analysis of clinical outcome after treatment for achalasia based on manometric subtypes. Br J Surg 2019;106:332-341.

24. Goldblum JR, Rice TW, Richter JE. Histopathologic features in esophagomyotomy specimens from patients with achalasia. Gastroenterology 1996;111:648-654.

25. Goldblum JR, Whyte RI, Orringer MB, Appelman HD. Achalasia. A morphologic study of 42 resected specimens. Am J Surg Pathol 1994;18:327-337.

26. Gockel I, Bohl JR, Doostkam S, Eckardt VF, Junginger T. Spectrum of 
histopathologic findings in patients with achalasia reflects different etiologies. J Gastroenterol Hepatol 2006;21:727-733.

27. Sodikoff JB, Lo AA, Shetuni BB, Kahrilas PJ, Yang GY, Pandolfino JE. Histopathologic patterns among achalasia subtypes. Neurogastroenterol Motil 2016;28:139-145.
28. Kilic A, Krasinskas AM, Owens SR, Luketich JD, Landreneau RJ, Schuchert MJ. Variations in inflammation and nerve fiber loss reflect different subsets of achalasia patients. J Surg Res 2007;143:177182. 